\title{
Moral and human rights education: the contribution of the United Nations
}

\author{
Murray Print ${ }^{\mathrm{a}}$, Carolina Ugarte ${ }^{\mathrm{b}}$, Concepción Naval*c ${ }^{* \mathrm{c}}$ and Anja Mihr ${ }^{\mathrm{d}}$ \\ ${ }^{a}$ University of Sydney, Australia; ${ }^{b}$ and ${ }^{c}$ University of Navarra, Spain; ${ }^{d}$ Humboldt \\ University of Berlin, Germany
}

Moral education can take many forms. With the end of the United Nations Decade for Human Rights Education (UNHRE) (1995-2004), we critically review developments in human rights education (HRE) during those ten years in the context of moral education. We argue that, despite some modest successes, the decade lacked direction and a major impact and has failed to prepare a sound basis for securing HRE internationally. These outcomes largely account for the United Nations' (UN) decision in 2005 to initiate the World Programme for Human Rights Education. Meanwhile initiatives in defining the goals and practice of HRE have happened outside the UN context. Overall the UN's contribution to building HRE and moral education has, at best, been marginally successful due in large measure to the inherent weaknesses of the organisation as well as the UN's inability to engage member states.

* University of Navarra, Edificio Central, 31080 Pamplona, Spain. Email: cnaval@unav.es 


\section{Introduction}

Moral education may take many forms within and outside schools and educational systems. While most initiatives in what generally constitutes moral education are typically bounded within formal educational systems and within countries, there are others which attempt to improve the human condition through international educational programs with no base anchored in any specific school or country. For example, some six decades ago the Universal Declaration of Human Rights (UDHR) extolled every individual and every part of society to 'strive by teaching and education to promote respect for these rights and freedoms'. Yet the record of human rights abuse has been so profound that by 1993 the United Nations (UN) declared a decade to promote training and dissemination of information to build a universal culture of human rights (UN General Assembly (GA), 1994).

Can an intergovernmental agency promote human rights education (HRE) effectively across and within national borders? In one sense the case of HRE and the UN, while apparently not as urgent as many others, typifies the rationale, need and dilemmas for such an agency - can the UN deliver improved human rights through engagement with HRE? Human rights, both as a concept and as an implementation strategy, are problematic for many governments and consequently there has been wide pressure for the UN to take action to enhance awareness through HRE. While other intergovernmental groups, such as the European Union, may take similar action, this paper focuses upon the work of the UN as it has taken a long standing position on human rights and HRE.

With the end of the United Nations Decade for Human Rights Education (UNDHRE) in 2004, it is important to critically review the actions undertaken by the United Nations and to identify the impact of the program on human rights education specifically. Special mention has to be made of the task of the Office of the United Nations Commissioner for Human Rights (OUNHCHR), charged with coordinating the Plan of Action of the Decade, which has worked together with organisations such as the United Nations Educational Scientific and Cultural Organisation (UNESCO) and nongovernmental organisations. This review is based partly on official documents published by the UN, such as the United Nations Decade for Human Rights Education, 1995-2004 (Office of the United Nations High Commissioner for Human Rights, 1998) and the Report of the United Nations High Commissioner for Human Rights on the mid-term global evaluation of the UNDHRE (UN GA, 2000) 
On December 10th 2004, the international day for human rights, the UN General Assembly concluded the Decade, but saw the need for the international community to continue collaborating to realise effective education for human rights. Simply put, too many objectives of the Decade for education in human rights were not achieved. The establishment of a UN World Programme for Human Rights Education (WPHRE) was approved with its first phase extending UN involvement in HRE to 2007. The purpose of this paper then is to outline, in the context of moral education, the definition and meaning of HRE, to explain the initiatives, to detect the strengths and weaknesses of the Decade and to identify trends within the framework of the WPHRE.

\section{Moral and human rights education}

While much of human rights is concerned with aspects of law, human rights education focuses its attention on changing human behaviour to address issues of human rights. Over the past two decades increasing concern has been expressed at the lack of improvement in the general condition of human rights around the world (Davies, 2000; Georgi \& Soberich, 2004). One early identified approach to tackle human rights issues has been to promote the widespread application of HRE (UN. GA, 1994; UN Commission on Human Rights, 2004; Mihr, 2004). However, the status of HRE around the world, while variable, is generally low in terms of explicit national educational goals within countries. Indeed, this was a major motivation for calling the World Conference on Human Rights in 1993 (UN CHR, 2004; Australia. Joint Standing Committee on Foreign Affairs, Defence and Trade (AJSCFADT), 2004; Mihr, 2004).

In the process HRE has sought to gain wider public appeal, including establishing logical linkages with civic education, citizenship education and moral education. Several components of HRE may be linked directly with a broadly interpreted moral education, including capacity building within individuals to act morally towards others, awareness of fundamental moral positions, such as the value of human life, and building understanding of the impact of policies upon people's lives through education (Osler \& Starkey, 2000).

As a constitutive element of education HRE extends throughout life, affecting all social groups. Hence education in human rights may also be seen as the basis of moral, civic or anti-bias education. Moral education may be regarded as education of, in and for freedom and moral responsibility; whereas civic education is education that facilitates the kind of human co-existence that is necessary for the common good 
(Medina, 1986). Therefore, a person educated in human rights, making free, morallybased decisions and actions, could contribute towards social justice and hence the common good of all in society (Naval, 2000).

Significant attempts to address issues which are fundamental to moral education and which attempt to improve the human condition may be found in international educational programs, such as those proposed by the UN. Since moral education is directly concerned with developing morally aware and responsible people it is consequently linked with the more specific education about and for human rights. Indeed, it may be argued that both moral and human rights education are concerned with developing, through educational means, respect for fundamental human freedoms, a sense of dignity within people and the promotion of freedom, tolerance, equity and harmony amongst people.

Although HRE is a widely used expression in educational literature (Starkey, 1994; Readon, 1995; Satrath, 1998; Osler \& Starkey, 2000; Flowers, 2003; Mihr, 2004) here we wish to focus on HRE more narrowly in terms of what human rights education means in the context of the UN Decade. While definitional consensus for HRE is problematic, there is agreement that it is principally education in, of and for individuals, to build individual dignity and to accept that all have rights as human beings. For the purposes of the UN Decade, and for UN activities promoting human rights more generally, HRE was defined as training, dissemination and information efforts, aimed at building a universal culture of human rights through the imparting of knowledge, skills and attitudes directed to:

(a) The strengthening of respect for human rights and fundamental freedoms;

(b) The full development of the human personality and the sense of its dignity;

(c) The promotion of understanding, tolerance, gender equality and friendship among all nations, indigenous peoples and racial, national, ethnic, religious and linguistic groups;

(d) The enabling of all persons to participate effectively in a free society;

(e) The furtherance of the activities of the United Nations for the maintenance of peace (UNOUNHCHR, 1998).

To achieve such a level of individual understanding, the UN's HRE definition has identified the need for establishing a process for imparting the knowledge, skills and attitudes necessary to build a culture of human rights, to build understanding, attitudes and actions to protect human rights and to encourage peaceful, just and free communities. It has accurately argued, as agreed in the wider literature, that if citizens are not able to understand and state their human rights and those of others, they will not 
be able to claim these rights, nor will they be able to defend them if necessary - a fundamental concern of moral education (UNOUNHCHR, 1998; Davies, 2000; Naval, 2000; Flowers, 2003; Mihr, 2004).

In particular the UN definition highlights that HRE is concerned with the educational process whereby people learn about those rights that are arguably inherent in human nature and without which we cannot live as civilised human beings. Human rights and associated fundamental freedoms allow us to develop fully as humans and utilise our human qualities, our intelligence, our talents and our conscience, and to satisfy our other needs. They are based on mankind's increasing demand for a life in which the inherent dignity and worth of each human being will receive respect and protection (Flowers, 2003). As the first sentence of the Universal Declaration of Human Rights states, respect for human rights and human dignity 'is the foundation of freedom, justice and peace in the world' (UN CHR, 2004).

Definitions of human rights education have been strongly influenced by Paulo Freire's Pedagogy of the oppressed (1970), in which he provides a blueprint for resistance to oppression as well as for empowerment of the individual to become an active member of society and overcome discrimination, poverty and inequality. Recently the Internet-based non-government organisation (NGO), Human Rights Education Associates (HREA), started a new web-based discussion on the definition, goals and objectives of HRE. The consensus was that HRE is primarily the empowerment of the individual citizen to control his or her own life and decisions in order to overcome societal problems related to authoritative governments and structural problems within society, e.g. poverty and gender inequality. Secondly, HRE is to engage people of all ages to understand human rights, value it and take responsibility for respecting, defending and promoting it. Thirdly, HRE entails an ethical and political dimension. Fourthly, HRE educates people to develop their skills of empathy and sensitivity towards human rights, better communication, understanding similarities and valuing differences, avoiding prejudice and developing cooperative and creative problem-solving skills (http://www.hrea.net/decade). Thus the definition accepted by the UN is consistent with the literature in the field.

\section{The United Nations Decade for Human Rights Education}

Motivation for the UNDHRE reflected the lack of success in embedding human rights in the awareness and behaviour of people and countries since the original declaration in 
1948. Many nations were unable or unwilling to implement human rights within their borders with consequential pressure for intergovernmental action. Sustained abuse of human rights and a range of atrocities of all forms, such as genocide, illegal imprisonment, 'ethnic cleansing', torture, and human trafficking, provided the momentum for the 1993 World Conference on Human Rights in Vienna.

The most significant conference outcome was the declaration of the Decade, designed to engage individuals and countries in active support for human rights around the world. As approved by the UN General Assembly, the objectives were:

- Assessment of needs and the formulation of effective strategies for HRE at all school levels, in vocational training and non-formal learning.

- Building and strengthening international, regional, national and local programmes and capacities.

- Coordinated development of materials for HRE.

- Strengthening the role and capacity of the mass media to further HRE.

- Global dissemination of the Universal Declaration of Human Rights (UDHR) in the maximum number of languages possible, and in different materials or ways of diffusion, at different levels of literacy and for the disabled. (UN. GA, 1994)

Three principal guidelines inspired the subsequent reports, activities and initiatives of the UN Decade until 2004 (Ugarte, 2004). That none were highly successful is testimony to the inherent ineffectiveness of this UN approach to HRE and its inability to engage even a substantial minority of member states in cooperating with its resolutions and guidelines.

1. The UNDHRE 1995-2004 Lessons for Life. This document, containing the objectives and structure of the Decade for HRE, consisted of two parts: the International Plan of the Decade for Education in the Sphere of Human Rights, 1995-2004, and the Orientations for the Elaboration of National Plans of Action for Education in the Sphere of Human Rights. The Plan of Action -first part of the document- drew attention to those aspects that appear to have greater relevance for educating people about human rights (UNOUNHCHR, 1998).

These documents and the general momentum of the Decade were significantly influenced in their application by the UN Guidelines for the Decade (UN. GA, 1994; UNOUNHCHR, 1998) which revolved around the implementation of a national plan for HRE based upon:

- Establishing a national committee for HRE

- Conducting a baseline study of current HRE 
- Setting priorities and identifying groups in need

- Developing a national plan

- Implementing the national plan, and

- Reviewing and revising the national plan

The Plan of Action, as seen above, was designed primarily to develop a national policy for HRE and second, to engage educational institutions in implementing that plan. There was, therefore, a potential problem between the global intentions of the Decade and the national applications of individual countries.

2. The mid-term global evaluation of the achievement of the UNHRE objectives. In 2000 the UNOUNHCHR reported on an evaluation of the first five years of the Decade. This evaluation aimed at determining the achievements at international, regional, national and local levels, as well as identifying deficiencies and necessities for change. It also formulated recommendations for the five remaining years of the Decade.

The mid-term report clearly reveals that the initiatives carried out by the UN and the national, regional and local entities, as well as the supervision, application and evaluation of the Decade, and the resources assigned, were insufficient to meet the stated objectives. The UN itself verified that proposed programs were not sufficiently part of the educational policies of the different countries and, as a result, had not been sufficiently implemented in schools (UN. GA, 2000). The report also identified other weaknesses in the application of the Decade's activities - the lack of awareness and knowledge of human rights transmitted through the HRE, the lack of appropriate participative pedagogical methods in schools and the ongoing struggle to decrease human rights violations in the world.

A fundamental weakness identified was that so few countries responded to the review questionnaire that the international picture was grossly inadequate. By omission the great majority of countries had not adopted national action plans, with even fewer implementing them. The report identified many countries were uncertain about the applied meaning of HRE and how HRE should be implemented in both the formal and non-formal education sectors. In addition, the UNOUNHCHR identified a lack of political will and financial support for HRE programs in almost all UN member states (UN. GA, 2000). 
3. The final report on the UNDHRE. This together with the official judgement on the Decade, which has not been presented to the public as yet (though it was due in November 2005), is the task of the UNOUNHCHR in cooperation with UNESCO. As the outcomes of the decade are well known the final report will be of little value apart from determining the 'advancements' made in different spheres of the Decade.

\section{A decade of failure for Human Rights Education}

It has been widely accepted, especially by the UN itself, that, despite some modest successes, the Decade lacked direction and impact and failed to prepare a sound basis for securing HRE internationally (UN. GA, 2000; UNHCHR, 2004; AJSCFADT, 2004). Nowhere is this more evident than in the 2005 announcement of the World Programme for HRE which was tantamount to evidence that the Decade had, in effect, failed. This outcome was already well known by the UN from the formative self-evaluation of the Decade after the first five years. In a telling self-revelation the UNHCHR's mid-term report on the achievement of the Decade's objectives noted that member governments had far to go to achieve the desired outcomes (UN. GA, 2000). Indeed, the review wryly observed that 'The occasion of the fiftieth anniversary of the adoption of the Universal Declaration ...appears to have had a greater catalytic impact on the United Nations system than has the Decade' (UN. GA, 2000, p. 19).

Is the UN, through the UNOUNHCHR and its HRE program, capable of affecting education about human rights in different countries, and hence moral education internationally, in any meaningful way? Or was the decade of HRE little more than window dressing for an increasingly ailing and dysfunctional international organisation? The measures proposed for the Decade to carry out HRE focused on international, national, regional and local plans. In seeking to explain why the Decade has been so ineffective we can identify five major factors - member state engagement, individual engagement, teaching and schools, UN weaknesses, and the participation of NGOs.

\section{Engaging member states and national policies}

A basic model of operation utilised by the UN to achieve its goals is to engage member states in wanting to achieve agreed outcomes through national policies. For HRE to be successful it has to be acknowledged through international agreements, such as UN 
resolutions, but expressed in national policies and legislation. To this effect, the Decade tried to promote the involvement of governments and decision makers with HRE, particularly through the promotion of National Plans of Action in member states (Mihr, 2004, 2005; UNHCHR, 2004). A great deal of the UN's efforts were concentrated on this, developing written procedural steps to be followed, and estimating the resources necessary to implement national policies within countries. Only a few dozen out of 191 member states actually followed this call and established National Action Plans, and even fewer provided assessment information on educational programs (UNHCHR, 2004). Indeed this trend was evident in the mid-decade evaluation (UN. GA, 2000), a fundamental weakness that the program was unable to resolve (UNHCHR, 2004; AJSCFADT, 2004).

Given the initial positive response to the World Conference in Vienna and the formation of the Decade, it was surprising that greater engagement of countries was not achieved. This lack of country engagement has been one of the principal obstacles to overcome during the Decade. Further, the initiatives undertaken in relation to HRE have, in some cases, been confined to the legislative sphere of the specific nations, and not implemented into educational practice to any degree.

Paradoxically the Decade had, in a small number of countries, the indirect effect of increasing the reporting of human rights abuses. As the UNHCHR (2004) report noted, efforts to increase HRE produced greater awareness of human rights and an increase in the subsequent reporting of HR abuses.

\section{Engaging individuals}

These consequences are only some of the manifestations of the theoretical propositions of human rights and education that underscore the actions undertaken by international organisations like the UN, UNESCO and the Council of Europe. Today human rights are conceived as rights to be guaranteed and protected only by state authorities. However, the aim of HRE is to prevent and eliminate human rights violations in the world through individual empowerment and activities, regardless of citizenship.

Thus HRE cannot be conceived only as a right to be protected and guaranteed by the state. Instead, HRE has to infuse social reality and for this to occur, it is essential that people commit themselves to the free and responsible exercise of their human rights. To this effect a legal framework that makes human rights possible in most countries is a necessary prerequisite, but it is also the responsibility of families, and then 
teachers, to educate the young in human rights. In this way the goal to educate citizens committed to their personal betterment and, in consequence, to the common good over a long term may be achieved.

To reach this goal, HRE means not only the transmission of knowledge, the acquisition of certain skills and adherence to accepted human rights values (UNOUNHCHR, 1998), but also requires the active teaching of human rights in schools. As a result, it demands from education systems opportunities for learning appropriate habits and virtues. Education in human rights can help a student discover the intrinsic goodness of the constitutive values of a dignified life, such as freedom, autonomy and personal responsibility, as well as respect for equality and personal differences. Such values include the democratic values of justice, solidarity, tolerance, peace and civic courage. Yet, as evidence of the many UN reports demonstrates, the Decade failed at the level of engaging individuals in HRE.

\section{Schools and human rights education}

A key objective of the Decade was to engage schools at all levels in effective strategies for HRE, as well as vocational training and non-formal learning situations. Incorporated within this intention was the notion of a HRE methodology that combined theoretical and practical education (Naval, 2000; Davies, 2000; Mihr, 2004). While theoretical education considers the fundamental concepts of human rights, practical education addresses the application of HRE, especially the attitudinal components of HRE. This includes the use of dialogical methods which are effective in developing skills of moral reasoning. To get students to 'live' the values implicit in human rights, it would be a good idea for them to implicate themselves in real or life-like situations (Print, Ornstrom \& Nielsen, 2002; Flowers, 2003; UNOUNHCHR, 2004; Mihr, 2004).

In particular school programs offer the opportunity to address issues which are central to both HRE and moral education. Through participative methods such as role modelling, group discussions and simulations, students would have opportunities to understand, appreciate and develop empathy in moral situations such as the role of individual freedoms, developing respect for others, and enhancing tolerance, equity and harmony amongst people (Davies, 2000; Print, et al., 2002). While this may have constituted the goal of HRE for schools in the Decade, the reality was far different.

That schools were not engaged adequately in HRE was recognised by the UN as a major shortfall of the Decade (UN. GA, 2000; UNHCHR, 2004). Countries largely 
failed to engage with their educational systems about HRE and hence their schools. Even if schools were involved in HRE, as in the case of Australia, involvement was frequently nominal (AJSCFADT, 2004). During the Decade this very central aspect of HRE can be described as 'shadowy' or elusive, as it undermined the transmission of knowledge about human rights and the use of dialogical methods to build human rights values. As many have commented (Naval, 2000; Osler, 2002; Flowers, 2003; Mihr, 2004), the social participation of students, as well as their capacity for reflection and analysis, should be considered essential in human rights education, yet this was largely absent from most countries as they failed to implement national policies (UNHCHR, 2004).

\section{Intergovernmental agency role}

Can an intergovernmental agency, such as the UN, play an effective role promoting HRE and impacting upon moral education within countries? The fundamental issue here is, given that the education of its people is a major right and responsibility of any government, can the UN intervene to address perceived shortcomings in HRE within any country? At best the United Nations might serve as a 'catalyst' to the transmission of information, as well as to the diffusion of international resources. It can encourage governments to engage with HRE and it can offer inducements in the form of human, technical and material resources to activate HRE within countries. But the UN's ability to directly intervene to establish a value-orientated society within countries that apply human rights in practice is severely limited.

Unsurprisingly the UN's declaration of the Decade contributed to the creation of a favourable, international culture committed to the realisation of HRE. But it only notionally facilitated decision makers, such as Ministries of Education and Police Ministries in many countries, to engage with HRE (Ugarte, 2004).

The UNOUNHCHR was charged with coordinating the Plan of Action of the Decade and worked together with organisations such as UNESCO, United Nations Development Programme (UNDP), United Nations Children's Fund (UNICEF) and NGOs. Many initiatives were undertaken and substantial resources produced (UNOUNHCHR, 2001, 2004). Yet by any measure it was not successful, as noted in the telling reports by the High Commissioner of Human Rights (UNHCHR, 2004). That one report included 'shortcomings of the Decade' in its title, speaks for itself. And that none of the activities were highly successful is testimony to the inherent ineffectiveness 
of the UN's approach to HRE and its inability to engage even a substantial minority of member states to cooperate with its resolutions and guidelines.

In addition to failing to engage with member states, the Decade was ineffective in enhancing change within countries through the implementation of educational programs (UNHCHR, 2004). Further, it became apparent that where educational programs did exist they invariably lacked appropriate methodologies for HRE, emphasising knowledge acquisition over participative learning (UNHCHR, 2004). And in many cases the ineffectiveness of implementation reflected the lack of resources, especially financial resources, available through the Decade.

Part of the overall problem with HRE must be attributed to the role played by the United Nations Commission on Human Rights (UNCHR), frequently described as 'dysfunctional', using double standards and 'completely broken' (Lauren, 2007). While these trenchant criticisms largely reflected the Commission's 'shielding' of human rights violators, they also characterised its inability to achieve its core business of human rights protection, including HRE. For multiple reasons therefore, the UN acting in its intergovernmental agency role, including the UNCHR and the UNOUNHCHR, was ineffectual in addressing, let alone achieving, the goals of the Decade.

\section{NGO participation}

For some time the UN has both recognised the role of NGOs in carrying out its purposes, as well as building ties with many NGOs, particularly the larger ones. However, the relationship between NGOs and UN policy implementation is complex, problematic and faces a conundrum. At one level the UN has come to rely upon NGOs to implement aspects of policy initiatives within and across national borders. In this way some of the UN's goals are at least addressed. For example, non-governmental organisations and private agencies initiated and implemented most of the work in the field of HRE until 2004, using the UN Decade as a catalyst to establish HRE programs and lobby state authorities. The Office of the High Commissioner for Human Rights states this in its report (2004), yet the work was incomplete because of the limited resources available to the NGOs.

NGOs, however, have other limitations beyond their funding, including their idiosyncratic, single-purpose nature, their reliance upon dedicated individuals and their all too frequent competition with each other for funding and public support. Finally, the UN noted that NGOs tend to concentrate upon human rights issues that relate to their 
specific mandate and often use human rights issues to seek support for their particular concerns rather than human rights generally (UN. GA, 2000). In turn then, any overreliance upon NGOs could weaken the very position the UN might take on policy. In terms of HRE it appears that NGOs, operating outside the formal school system, have been minimally successful in implementing the goals of HRE, and particularly the goals of the Decade (UNHCHR, 2004).

But the Decade was not a complete failure. Important initiatives in defining the goals and practice of HRE have happened outside the UN context due to the engagement of NGOs. There were also some positive government initiatives. For example, on numerous occasions the important links between human rights, democracy, peace and development have been highlighted (UNHCHR, 2004). Research on human rights has also been stimulated, and by so doing, the continued progress of this domain and teacher training are enhanced. The efficacious teaching of human rights in classrooms is directly linked to the success of such strategies. But for human rights to be respected, understood and applied in any country, a social and political climate that is favourable to the promotion of these rights is essential (Davies, 2000; Flowers, 2003; Georgi \& Soberich, 2004; Mihr, 2004). This remains a challenge for the United Nations.

\section{Australia: A case study of success?}

One useful way to reflect upon the success of the Decade is to identify how well it worked in practice within a country. How actively did Australia, a highly developed, generally pro-UN country, participate in the Decade? What did it do and why?

Australia has a tradition of recognising and endorsing UN resolutions and applying them internally. For example, Australia endorsed the Universal Declaration of Human Rights and the Covenant on Economic, Social and Cultural Rights. Indeed, at the 1993 Vienna World Conference on Human Rights, which recommended the Decade, Australia proposed that countries prepare a national action plan to ensure education on human rights was implemented (AJSCFADT, 2004). It could plausibly be argued that Australia would be likely to be a case study of success in implementing HRE. Initially that appeared to be the situation.

Australia became the first country to complete and submit a national action plan and consequently accepted the obligation to provide HRE as part of the Decade (AJSCFADT, 2004). However, democratic countries are subject to changes of government at the ballot box. Before HRE became well developed in Australia through 
implementing the action plan the Federal Government was defeated in the 1996 elections and replaced by a conservative government, less supportive of the UN. Subsequently the Australian Government took essentially two courses of action in regard to HRE. First, it argued that responsibility for HRE in the school sector lay with the Australian states. While constitutionally correct, the reality is that for any issue in which the Federal Government is interested it can find both the funding and the means to take the policy lead. Secondly, it passed most of its 'national responsibilities' to the specially formed Australian Human Rights and Equal Opportunity Commission and a National Committee on Human Rights Education (AJSCDFAT, 2004).

Indeed, the Australian Government later argued that it ' ... already had in place a comprehensive human rights strategy that went beyond the framework for human rights education established by the UN Decade...' (AJSCDFAT, 2004). But is this really the case? Has Australia exceeded the expectations of the Decade? Since 1996 the Australian Government's role as part of Decade has been to downplay its contribution to the UN and to pass responsibility for HRE to the Commission and National Committee, and then to all but ignore them and, in the case of the latter, all but starve it of funding (ANCHRE, 2003).

Given that school education in HRE was a nominated method to achieve the Decade's goals, the Australian approach was to rely upon the six states and two territories to engage the school curriculum. Through curriculum and assessment agencies, which control curriculum development within those eight jurisdictions, some effort was made to embed HRE within the Studies of Society and Environment component of the primary and secondary school curriculum. For example, a curriculum unit and school resources were prepared in New South Wales as part of the Human Society and its Environment syllabus for primary school students. Efforts to include HRE in tertiary education were made, with limited success (AJSCDFAT, 2004), as were efforts to engage the workplace and NGOs.

The fundamental problem for Australia achieving its Decade's goals, given its initial support for HRE, was a lack of co-ordinated effort to build HRE. As the ANCHRE commented in its submission to the AJSCFADT, 'There is an absence of any overall national coordination in human rights education. Compounding this lack of coordination is the absence of comprehensive and up to date bodies of data analysing the state of human rights education in the country. The lack of such data is a critical weakness in efforts to carry forward human rights education initiatives' (ANCHRE, 
2003, pp. 16-17). In all, therefore, despite an initial flourish, the case of Australia and HRE is one of neglect, low resource priority and lack of political will - an outcome found in the vast majority of countries.

In sum, the UN's contribution to building HRE and moral education in the Decade has been marginally successful due in large measure to the inherent structural weaknesses of the OUNHCHR/UNHCHR as well as the UN's inability to engage member states and their schools. Given the scanty positive results seen in the year prior to the conclusion of the Decade, the UNHCHR contemplated the possibility of announcing a Second United Nations Decade for Human Rights Education (UNHCHR, 2003; UNOUNHCHR, 2004). However, most countries viewed a second decade as an ineffective measure, arguing that another 'Declaration' and lip service commitment to HRE was of little value. What was needed was a realistic programme that would resonate with member states. Different options were considered and the first phase of the World Programme for HRE commenced on $1^{\text {st }}$ January, 2005 (UN. GA, 2004).

\section{World Programme for Human Rights Education}

Following the recommendations of the General Assembly, the UN Commission on Human Rights requested the establishment of a WPHRE (UN CHR, 2004). This Resolution asked for a Plan of Action centred on developing human rights education for primary and secondary schools. The UNCHR realised that a more direct involvement in school education was essential if young people were to learn about and practise human rights. The main components of the World Programme Action Plan are:

1. HRE in primary and secondary school systems

2. HRE implementation strategy at national level

3. National coordination of plan of action implementation

4. International cooperation and support

5. Evaluation of the world programme

A central feature of the WPHRE is the development of teacher competences and the creation of networks of experts and teachers to achieve these abilities. Only by including teachers and educators more centrally in the task of HRE, it has been argued, will society be part of the World Program. For this reason it has been deemed essential 
to train teachers and for educational policies at international and national levels to permeate school programs, teaching practice, and finally, reach the students.

But what should trainee teachers learn? First, they should acquire fundamental knowledge of human rights, value human beings, change attitudes and behaviour, and understand the conditions that make educational practices contribute towards human rights development (Mihr, 2004; Ugarte, 2004). When teachers undertake HRE they have to be aware that it is not enough to merely provide knowledge about human rights. It is important, but also more challenging, to teach skills and values.

A second significant aspect of HRE is a set of methodological strategies for both schools and teachers. These, it may be argued, should favour a disposition to dialogue, encourage student participation in the direction and organisation of their school, offer community service and engage students in civic matters to promote and defend human rights as part of participative pedagogies (Print et al., 2002), even if this means to take a stand against local authorities and traditional expository pedagogies.

Third, in order for WPHRE objectives to be achieved, they should form part of daily educational practice. After the experience with the Decade and current challenges to respect human rights worldwide there is more than ever a need for personal awareness to protect human rights. In order to avoid human rights violations, it is not enough to set legal frameworks or argue for governmental actions. It is essential to establish a culture of human rights throughout societies and achieve a long lasting commitment of people and individuals to participate in the free exercise of their human rights and those of others. This can be reached through implementation of HRE goals and methods within the formal and non-formal education sectors. Therefore, as argued by many in the educational field (Starkey, 1994; Davies, 2000; Naval, et al., 2002; Print, et al., 2002) the WPHRE should centre its efforts on proposing educational measures more closely linked to the realities of the different educational communities, such as citizenship education, where this is located in the school curriculum.

However, the responsibility for teacher education and teacher professional development does not rest with the UN but with various agencies (eg state education departments, religious education agencies, secular education agencies, universities) within member states. Further, unless the country has a national education system with central control, the constitutional power for education may also be vested with state/ provincial governments. Thus implementation of HRE policies and teaching practices is 
impossible without strong support from member states, just as was the case with the Decade.

Aware of these limitations the WPHRE intends to overcome the weaknesses of the Decade by promoting a more structured approach, using consecutive phases that would be internationally implemented with clear implications for each country. It has planned a more proactive approach including encouraging HRE in national legislation, developing curricula suitable for schools, producing school teaching materials, encouraging the use of participative methodologies and different pedagogical tools, such as the Internet. Additionally, it will establish an international structure for cooperation between governments and civil society - which again will mean a strong engagement of NGOs. And while the aim of the UN Decade centred on promoting HRE from political, legal, organisational and structural points of view, the WPHRE views HRE as a specific learning activity in primary and secondary schools and as an asset to the whole of society, with a more direct call for social participation and partnership with the whole society.

While the WPHRE was to build on the UNDHRE, during the consultations a majority of the countries insisted the program be exclusively financed with voluntary contributions (UN. GA, 2005). Thus the program is not expected to be widely supported since most countries barely resource basic education for their citizens, let alone support HRE. Nevertheless, the Office of the High Commissioner for Human Rights in Geneva is fully committed to do its best to support any initiative in this area, establish networks and monitor the implementation process (UN. GA, 2007, January, March). Simultaneously, the WPHRE aims, in many countries, to develop the human rights competences of personnel in state authorities, such as Ministries of Justice, Education, Social Affairs and Health as well as the armed and police forces.

Nevertheless, despite these attempts at a more integrated, engaging approach to HRE it will most likely be that NGOs, private foundations and activists will carry out the majority of the program. They have a legal base to rely on and can lobby state authorities to support their efforts to implement HRE in formal and non-formal education sectors. However, they can never replace governmental engagement and commitments because they lack the legislative/constitutional mandate over formal education, and have limited influence and resources. Hence NGOs and private initiatives can only provide limited support for HRE. 


\section{World Programme for Human Rights Education - a success?}

Does the WPHRE appear to be any more successful than its predecessor? Is there any evidence that HRE is being implemented in member states, or are the failures of the Decade being replicated? Within the UN at least, the WPHRE appeared to have commenced well. By the end of 2006 the foundations had clearly been laid (UN. GA, January, 2007). In summary:

- The Human Rights Council was established early in 2006 by the UN General Assembly

- Several UN committees have engaged with HRE

- OHCHR has carried out joint activities with UNESCO

- WPHRE information disseminated to Ministers of Education in countries

- OHCHR and UNESCO hosted the first meeting of the UN Inter-Agency Committee on HRE in schools and developed HRE strategy to promote HRE in schools

- OHCHR has also contributed to HRE through networking, supporting technical cooperation, supporting community level education initiatives by NGOs and disseminating information on human rights and HRE (UN. GA, 2007, January).

However, by December 2006, only 28 governmental bodies had responded to the request for information about plans of action for WPHRE. A wide range of countries responded from Bulgaria to Iraq to New Zealand and Portugal, though not Australia and only Japan would be considered a major world power. In responding, governments are obligated to report regularly on their efforts to implement HRE, for example through regular reports to other UN Committees, such as on Social, Cultural and Economic Rights and the Committee on Human Rights. These are not onerous reporting requirements and reflect more the member state level of apathy towards the $\mathrm{UN}$ inspired WPHRE.

Furthermore, signs of frustration with the WPHRE, and the newly established Human Rights Council (HRC) itself, are already evident. In a joint NGO statement to the HRC, a group of NGOs urge greater resources for HRE to be made available (UN. GA, 2007, March). There is a further request that HRE become a priority item for the HRC, to mainstream HRE within education systems and to make the development and implementation of national policies an indicator in HRC evaluations. The NGOs also sought to extend the first phase of the WPHRE, due to what they recognised as the slow pace of national implementation as evidenced by the low response rate from countries. 


\section{Conclusions}

The UNDHRE was a noble and necessary, yet inherently flawed, approach to human rights education by the UN. It realised the need to educate people, particularly the young, to understand and practise human rights for themselves and for others. Yet, despite the support of the UN, it was unable to achieve its goals to any significant degree. It has been widely accepted, both with the UN community and outside, that the Decade failed to meet its intentions as it lacked direction and impact and was unable to engage member states to prepare a sound basis for securing HRE.

That many aspects of HRE are clearly linked with moral education has become evident as efforts in HRE have progressed. These include providing educational opportunities to develop individual capacities to act morally towards others, developing awareness of fundamental moral positions, such as the value of human life, and building understanding of the impact of policies upon people's lives through education. Moreover, as HRE is understood as a lifelong engagement it is also a constituent component of moral education, particularly where the latter argues for human freedoms.

The approval of the WPHRE in December 2004, after the acknowledged failure of the Decade, meant a new commitment of the international community in favour of HRE and a renewed opportunity to enhance moral education. The principal lines of the WPHRE underscore two central aspects of this education: the necessary engagement of teacher training in HRE and the use of participatory methodologies to improve individual skills of students to defend their human rights and the human rights of others. This is important because effective HRE it is not about knowledge alone, but to promote and change habits of conduct and behaviour which are consistent with human rights.

Yet, despite a more promising beginning, the WPHRE appears to be following the directions of its predecessor. Until the UN and its agencies gain greater clout, or member states can be encouraged or coerced to participate with agreed, fundamental principles, the process will remain ineffective. Reflecting on the UN's contribution to building HRE and moral education over the period of the Decade and in to the WPHRE, it has, at best, been marginally successful, due in large measure to the inherent weaknesses of the organisation as well as the UN's inability to engage member states in institutionalising HRE. 


\section{References}

Australia. Joint Standing Committee on Foreign Affairs, Defence and Trade (AJSCFADT) (2004) Human rights and good governance education in the Asia Pacific Region (Canberra, Parliament of Australia).

Australia. National Committee on Human Rights Education (NCHRE) (2003) Submission to Joint Standing Committee on Foreign Affairs, Defence and Trade (AJSCFADT Australia) (Canberra, Parliament of Australia).

Davies, L. (2000) Citizenship education and human rights education: key concepts and debates (London, British Council).

Flowers, N. (2003) A survey of human rights education (Hamburg, Bertelsmann Verlag).

Freire, P. (1970) Pedagogy of the oppressed (New York, Continuum Publishing Company).

Georgi, V. \& Soberich, M. (Eds) (2004) International perspectives in human rights education (Berlin, Bertelsmann Foundation).

Human Rights Education Associates (HREA) http://www.hrea/lists/hreducation/markup/msg01511.html and http://www.hrea.net/decade

Lauren, P. (2007) To preserve and build on its achievements and to redress its shortcomings: the journey from the Commission on Human Rights to the Human Rights Council, Human Rights Quarterly, 29, 303-345.

Medina, R. (1986) Educación moral y comportamiento cívico-político [Moral Education and Civic - Political Behaviour], Revista Española de Pedagogía, 173, 315-338.

Mihr, A. (2004) Human rights education: methods, institutions, culture and evaluation, Discussion papers, Vol. 4, Mandeburg, University of Magdeburg, Germany. Available online at: www.humanrightsresearch.de (Accessed 30th October 2007).

Naval, C. (2000) Educación y derechos humanos [Education and Human Rights], Humana Iura, 10, 43-59.

Naval, C., Print, M. \& Veldhuis, R. (2002) Education for democratic citizenship in the new Europe:context and reform, European Journal of Education, 37, 2, 107-128.

Osler, A. (2002) Education for human rights and citizenship in a multicultural society: making a difference, Citizenship, Social and Economics Education, 5 (1), 5-16.

Osler, A. \& Starkey, H. (2000) Human rights, responsibilities and school selfevaluation, in: A. Osler (Ed.) Citizenship and democracy in schools: diversity, identity, equality (Stoke-on-Trent, Trentham), 91-112.

Print, M., Ornstrom, S. \& Nielsen, H. (2002) Education for democratic processes in schools and classrooms, European Journal of Education, 37 (2), 193-210.

Reardon, B. (1995) Educating for human dignity: learning about rights and responsibilities (Philadelphia, University of Pennsylvania Press).

Satrath, K. (1998) Education for human rights and democracy (Paris, UNESCO).

Starkey, H. (1994) Development education and human rights education in A. Osler, (Ed.) Development education. Global perspectives in the curriculum (London, Cassell).

Ugarte, C. (2004) Las Naciones Unidas y la educación en derechos humanos [United Nations and Human Rights Education] (Pamplona, EUNSA).

United Nations. Commission on Human Rights (1999) Report of the United Nations High Commissioner for Human Rights on the implementation of the Plan of Action for the United Nations Decade for Human Rights Education, (E/CN.4/1999/87) (United Nations, Geneva). 
United Nations. Commission on Human Rights (2000) Report of the United Nations High Commissioner for Human Rights on the implementation of the Plan of Action for the United Nations Decade for Human Rights Education, (E/CN.4/2000/93) (United Nations, Geneva).

United Nations. Commission on Human Rights (2002) Report of the United Nations High Commissioner for Human Rights on the implementation of the Plan of Action for the United Nations Decade for Human Rights Education, (E/CN.4/2002/104) (United Nations, Geneva).

United Nations. Commission on Human Rights (2004) United Nations Decade for Human Rights Education (1995-2004), Report on achievements and shortcomings of the Decade and in future United Nations activities in this area, (E/CN.4/2004/93) (New York, United Nations).

United Nations. General Assembly (1994) United Nations Decade for Human Rights Education, Resolution adopted by the General Assembly, United Nations (A/RES/49/610/Add.2) (New York, United Nations).

United Nations. General Assembly (2000) Report of the United Nations High Commissioner for Human Rights on the mid-term global evaluation of the progress made towards the achievement of the objectives of the United Nations Decade for Human Rights Education (1995-2004), United Nations (A/55/360) (New York, United Nations).

United Nations. General Assembly (2004) Draft plan of action for the first phase (20052007) of the World Programme for Human Rights Education, United Nations, (A/59/525) (New York, United Nations).

United Nations. General Assembly (2005) World Programme for Human Rights Education, Resolution adopted by the General Assembly, United Nations, (A/RES/59/113) (New York, United Nations).

United Nations. General Assembly (2007, January) Implementation of General Assembly Resolution 60/251: Human Rights Council. Report of the UNHCHR, United Nations, (A/HRC/4/85) (New York, United Nations).

United Nations. General Assembly (2007, March) Implementation of General Assembly Resolution 60/251: Human Rights Council. Joint NGO statement, United Nations, (A/HRC/4/NGO/90) (New York, United Nations).

United Nations High Commissioner For Human Rights (2003) Promotion and protection of human rights. Study on the follow-up to the United Nations Decade for Human Rights Education (1995-2004). Commission on Human Rights, United Nations (E/CN. 4/2003/101) (New York, United Nations).

United Nations. Office of the United Nations High Commissioner for Human Rights (1998) United Nations Decade for Human Rights Education 1995-2004. Lessons for life (HR/PUB/DECADE/1998/1) (New York and Geneva, United Nations).

United Nations. Office of the United Nations High Commissioner for Human Rights (2001) Compendium of national plans of action for human rights education (Geneva, United Nations).

United Nations. Office of the United Nations High Commissioner for Human Rights (2004) Summary of national initiatives undertaken within the Decade for Human Rights Education (1995-2004) http://www.ohchr.org/english/issues/education/training/initiatives.htm (Accessed 30 th October 2007). (Geneva, United Nations). 


\section{Abbreviations}

AJSCFADT: Australia. Joint Standing Committee on Foreign Affairs, Defence and Trade

ANCHRE: Australia. National Committee on Human Rights Education

GA: General Assembly

HRC: Human Rights Council

HRE: Human Rights Education

HREA: Human Rights Education Associates

NGO: Non-governmental organisations

UDHR: Universal Declaration of Human Rights

UN: United Nations

UN CHR: United Nations Commission on Human Rights

UNDHRE: United Nations Decade for Human Rights Education

UNESCO: United Nations Educational Scientific and Cultural Organisation

UNHCHR: United Nations High Commissioner for Human Rights

UNOUNHCHR: United Nations Office of the United Nations High Commissioner for Human Rights

WPHRE: World Programme for Human Rights Education 